\title{
BIG FIVE PERSONALITY TRAITS AND WORKPLACE SPIRITUALITY: A MIXED METHOD STUDY
}

Hasan Tutar, Emre Oruç, Ahmet Tuncay Erdem, Harun Serpil

\section{Abstract}

This mixed method study aims to examine the relationship between big-five personality traits and workplace spirituality from a managerial perspective by analyzing its potential effects on management. In the quantitative step, the cross-sectional survey was employed as the data collection, and the data were obtained from a sampling group through the simple random sampling. Further, the qualitative part of the study was designed as a purposive sampling technique. The quantitative research data were obtained from 238 participants working in a public university in Turkey. The qualitative data were obtained by interviewing a group of 14 people from the same sample of participants working as administrators at the same university. The qualitative data of the study were analyzed by content analysis. The findings indicate that the harmony between the perception of personality structures and workplace spirituality has an important function in the adoption of workplace values by the employees.

Keywords: Organizational psychology, Personality traits, Workplace spirituality, Job satisfaction, Organizational values.

JEL Classification: M10,M12, M54

\section{INTRODUCTION}

The perceptions, attitudes and behaviors of people towards a given phenomenon or event differ from each other; the main reason behind this fact is that people's "personal traits" are different. Hence, it can be argued that the difference in personal traits might cause distinct perceptions of workplace spirituality. However, considering the differences in personality traits, is it the right approach to manage people with the same management principles and rules and to think that everyone gives the same meaning to the same practice? Considering the potentially high number of employees, another challenge is delivering a management style that addresses individual personality traits without causing a chaos. Another question is whether it is possible to have an understanding of

\author{
Hasan Tutar, Prof. Dr. \\ Professor \\ Faculty of Communication \\ Bolu Abant Izzet Baysal University \\ E-mail: hasantutar@ibu.edu.tr
}

Emre Oruç, $\mathrm{PhD}$ (corresponding author)

Assistant Professor

Gölpazarı Vocational School

Bilecik Şeyh Edebali University

E mail: emre.oruc@bilecik.edu.tr

Address: Bilecik Şeyh Edebali University, Gölpazarı Vocational School, 11700, Gölpazarı, Bilecik, Turkey

Ahmet Tuncay Erdem, PhD

Assistant Professor

Faculty of Communication

Bolu Abant Izzet Baysal University

E-mail: ahmeterdem@ibu.edu.tr

Harun Serpil, PhD

Assistant Professor

School of Foreign Languages, Anadolu University

E-mail: hserpil@anadolu.edu.tr 
management that does not ignore the personality differences of the employees and combines their differences on a common ground within the framework of respect and understanding. Answering all these questions requires that the concepts of personality traits and workplace spirituality be dealt with together. There are important intersections between the lower dimensions of personality traits and the lower dimensions of organizational spirituality. These questions are examined within the framework of the relationship between personality characteristics and the perception of workplace spirituality.

The main goal of this study is to probe into a management understanding that does not ignore the variability of employee personal traits, but unites all their differences within the framework of respect and understanding that strengthens organizational ability to do business.

\section{THEORETICAL BACKGROUND}

Personality, which distinguishes a person from others and makes one unique, is the whole set of invariable traits of a person. In other words, personality is a determined and stable structure which is a result of personal differences in feelings, ideas, and behaviors. Personality is the sum of both the innate and acquired characteristics of an individual, making a person distinct from others. It is the unique reflection of all the factors affecting behavioral styles of people (Hough and Ones 2001). According to Burger (2008), personality stands for "consistent behavior patterns" and "intrapersonality processes". Consistent patterns of behavior are related to the continuous, stable and coherent structure of personality, while intra-personality processes include all emotional, motivational, and formal processes that affect how a person behaves and feels.

The second variable of the study, workplace spirituality, is defined as the inner peace of an individual in his or her working life, feelings of integration with the culture and values of his or her colleagues and workplace, and the general state of well-being, which are all related to personality traits (Petchsawang and Duchon 2009). As a matter of fact, workplace spirituality is a set of values that enable employees to experience a sense of spiritual well-being and drive them towards their goals. The internal state of peace that employees perceive in the organizational environment, their level of satisfaction with themselves and their duties are directly related to their personality.

Studying the relationship between personality traits and workplace spirituality, some researchers have examined them as independent concepts (Garcia-Zamor 2003; Milliman, Czaplewski, and Ferguson 2003), while some regarded spirituality as a dimension of personality (Lazar 2016). Hence, it is important to find out which dimensions of personality relate to which aspects of workplace spirituality. Revealing such particularities of personality traits and the way they affect workplace spirituality will contribute to practice, method and theory. Personality traits are based on "traits theory" which explains the phenomenon of personality by the features which distinguish a person from others and make a person unique, reflecting an individual's mental, physical, and psychological differences on his/her own behavior and lifestyle (Bozionelos 2004). The Five-factor model of personality is the model of evaluation that defines personality in the most detailed way (McCrae and Costa 2003). Goldberg (1981) developed the traits theory based on his study on the adjectives describing the word "personality," and identified the big five dimensions of personality. Burger (2008) notes that "the most common features constituting personality can be explained by big five personality dimensions." Although not all researchers agree on the dimensions of personality, the personality literature concurs on the following big five personality dimensions: openness, conscientiousness, extraversion, agreeableness, and neuroticism (Somer and Goldberg 1999).

Openness: An active imagination, aesthetic sensitivity, intellectual curiosity, flexibility and nontraditional attitudes and the ability of independent judgment are among the characteristics of the personality that is open to new experiences. Those getting high scores on openness are the people who are exceptional, willing to question authority, and sensitive to ethical, social, and political issues. They tend to participate in intellectual activities and are open to brand new ideas. They are eager to experience new things, are creative, equipped with analytical thinking, and sensitive/open to other opinions (Glass et al. 2013).

Conscientiousness: They are success-oriented, hardworking, reassuring, responsible, careful, neat, planned, and organized people with a high sense of loyalty towards work and organization. These people have a high degree of impulse control, with the following sophisticated traits: Following norms and rules, being neat and prudent, responsible, devoted, being organized, and hardworking (Witt et al. 2002). Conscientious employees are keen on their jobs, are organized and determined, have high self-control, are ambitious, and willing to achieve their goals (John, Naumann, and Soto 2008).

Extroversion: This dimension of personality includes the traits such as sociability, assertiveness, effectiveness, and talkativeness. The people with extroversion 
personality type are independent, active, and sociable. This dimension represents an individual's sociability and friendliness. Other features include the following: graciousness, warmth, gumption, daredevilry, cordiality, sociality, and sensation seeking (McCrae and Costa 2003).

Agreeableness: The people with high agreeableness are usually self-sacrificing, sympathetic, and helpful and display relatively honest, polite, and pro-social behaviors. They are caring and concerned people who are more prone to teamwork with high empathy skills. These people are modest, cooperative and sincere (Tett, Jackson, and Rothstein 1991).

Neuroticism: This personality dimension shows a continuum that ranges from emotional stability to emotional imbalance. Neurotic people have low emotional stability, and they are reluctant to interact with others. They tend to show anxiety and negative feelings such as depression, apprehension, and anger. The individuals with high levels of neuroticism are anxious, restless, upset, and have poor ability to cope with stress (Glass et al. 2013).

Spirituality refers to subjective awareness, sense of integrity, inner satisfaction, and self-consciousness that are a part and parcel of personality (Ashmos and Duchon 2000). Although some studies attempt to establish a relationship between religion and spirituality, workplace spirituality is used in a different sense from the concept of religion. While workplace spirituality reflects some psychological factors related to tolerance, sense of commitment, and adoption of organizational norms brought together to shape personal values, religion can be described as a belief system that excludes any questioning. As Giacalone and Jurkiewicz (2003) point out, linking workplace spirituality to religious beliefs originates from the lack of a commonlyaccepted definition of workplace spirituality.

Workplace spirituality consists of values that regulate working relationships in the work environment, and workplace spirituality refers to the level at which an individual moves towards his or her ultimate goal in work life, develops strong connections with colleagues and others involved in work, and sees harmony between his/her beliefs and workplace values (Mitroff and Denton 1999). All these behaviors displayed in the workplace cannot be addressed independently of personality. Internal perceptions and understanding of the work environment, the whole of the climate, beliefs and values that dominate the organization are influenced by the inner spiritual qualities and personality traits that employees perceive in the workplace (Nasina, Pin, and Pin 2011; Saks 2011). Workplace spirituality is the entirety of employees' own inner lives, and spiritual feelings in their interpersonal relationships (Sheng and Chen 2012; Garcia-Zamor 2003). Positive workplace spirituality reflects the psychological, mental and physical wellbeing that one perceives in the organization.

The intertwined relationship of an individual with him/herself, other people, and nature with high inner peace is the level of harmony between his/her own beliefs and workplace values. Petchsawang and Duchon (2009) define workplace spirituality as the inner peace of the individual in his/her working life, feelings of integration with the culture and values of his/ her colleagues and workplace, and general well-being. Workplace spirituality is based on values that enable employees to experience a sense of spiritual well-being in the work environment and motivate them towards their goals. The perceptions of workplace spirituality differ by personality traits. Since personality trait is the most important determinant of workplace spirituality perception, handling workplace spirituality and personality traits together seems reasonable.

The workplace spirituality in the present study is based on the theory of work psychology, which is one of the applied subfields of psychology that examines the causes of behaviors in the workplace and provides a viable framework for explaining the relationship between personality and workplace spirituality (Duffy et al. 2016). Workplace spirituality is the "immanent" and "transcendent" mood states that employees experience in the workplace. Immanency refers to employee personal desires and the way that they devote themselves to the service of a greater "good" by integrating their inner lives with their professional roles. The transcendence is the desire to do something useful for others (Giacalone and Jurkiewicz 2003). Positive workplace spirituality perception contributes to strengthening employee feelings of cooperation, creating a creative organizational culture with high representation ability, and creating a sense of mutual loyalty and trust among employees (Afsar and Rehman 2015).

Workplace spirituality are examined in three dimensions: meaningful work, sense of community, alignment with organizational values (Milliman, Czaplewski, and Ferguson 2003).

Meaningful work: This basic dimension refers to the level of an individual's attributing meaning to his/her own work. Emotions such as employees' taking initiative in the job, motivation, the meaning attributed to oneself and others, and satisfaction with work relate to the concept of meaningful work (Daniel 2010). This dimension also involves the search for meaning in the job, the realization of a dream, making contribution to others, and the purpose of creating added value (Neal and Biberman 2003). The employee's use of initiative at work, motivation, the meaning they attribute 
to oneself and others, and work satisfaction are some otherpersonality factors (Kinjerski and Skrypnek 2006; Daniel 2010). This dimension is about giving more meaning to the lives of oneself and others depending on each person's personality traits which involves pursuing a dream, and contributing to others (Ashmos and Duchon 2000; Neal and Biberman 2003). It is associated with personality traits such as openness to experience, an active imagination, aesthetic sensitivity, intellectual curiosity, and the ability to make independent judgment (Glass et al. 2013). It is further associated with the conscientiousness subdimension of the personality, with characteristics such as successorientedness, high organizational loyalty, being hardworking, responsible, careful, and orderly (Witt et al. 2002; John, Naumann, and Soto 2008) in addition to the compatibility subdimension, expressed through altruism, pro-community behaviors, and relation to other people.

Sense of community: Related to the interactions among employees, the sense of community reflects the level of harmony between organizational values and employee values (Piryaei and Zare 2013). It stems from the employee desire to establish strong relationships with colleagues based on the belief that people are related to each other and that there is a connection between their own selves and the selves of others (Milliman, Czaplewski, and Ferguson 2003). A sense of community refers to the mental, emotional, and spiritual connections between employees. This dimension is closely related to the openness to experience dimension of personality traits, such as aesthetic sensitivity, intellectual curiosity, openness to new thoughts, openness to other views and sensitivity. It is also associated with the dimension of conscientiousness, exhibited by strong impulse control and being responsible, careful, and orderly; with extraversion characteristics such as sociability, assertiveness, activeness and talkativeness, and compatibility, which includes being polite, showing pro-community behaviors, and caring for other people (Glass et al. 2013; McCrae and Costa 2003; Witt et al. 2002).

Alignment with organizational values: This dimension of workplace spirituality refers to the level of harmony between the personal values of the individual and the values of the organization (Mitroff and Denton 1999). Related to interpersonal relationships, alignment refers to the degree to which an individual participates in interpersonal cooperation. Those who cooperate with others are friendly, sociable and trustworthy people. Alignment with organizational values is not only aimed at the individual itself, but also requires contributing to others (Milliman, Czaplewski, and Ferguson 2003). This dimension is associated with the openness dimension of personality, indicating eagerness to try new experiences (Glass et al. 2013), as well as with the conscientiousness dimension characterized by dedication to following rules (John, Naumann, and Soto 2008; Witt et al. 2002). This dimension is also related to the extroversion dimension of the personality characterized by proactivity, sociability, friendliness, warmth, and assertiveness (McCrae and Costa 2003). Considering the above-mentioned dimensions of the concept and the overlapping aspects of the definitions are together, workplace spirituality emerges as the totality of employees' spiritual feelings and interpersonal relationships (Sheng and Chen 2012).

This study aims to find out whether personality traits affect the perception of workplace spirituality and provide support for this effect from a qualitative perspective.

The main hypothesis of the study "whether personality traits affect the perception of workplace spirituality." As such, the following hypotheses were developed for the quantitative part:

The sub-hypotheses:

$\mathrm{H} 1$ : Openness to innovations affects workplace spirituality positively and significantly.

H2: Emotional stability affects workplace spirituality positively and significantly.

H3: Extraversion affects workplace spirituality positively and significantly.

H4: Agreeableness affects workplace spirituality positively and significantly.

H5: Neuroticism affects workplace spirituality negatively and significantly.

\section{METHODOLOGY}

\subsection{Research Design}

This study adopts both the quantitative method based on positivist epistemology and the qualitative method based on interpretive/constructivist epistemology. The mixed method research design was a pragmatic choice because it explains a given phenomenon better by combining the strengths of both quantitative and qualitative methods (Creswell and Garrett 2008; Johnson and Christensen 2004; Tashakkori and Teddlie 2003). Predictive design was used as the model of the quantitative part of the study (Creswell 2012). Besides allowing deductive reasoning, the quantitative method enables objective measurements, and fits the purpose of testing hypotheses and generalizing results (Creswell and Poth 2018; Glesne 2015; Patton 2014). Applying the qualitative method to combine the quantitative findings with the qualitative results was 
essential for the purpose of solving or better understanding a practical problem, developing alternative perspectives, and taking advantage of inductive reasoning. As it is convenient to examine current cases, the "case study" design was preferred for the qualitative part (Creswell and Poth 2018; Yin 2014). The case study design in the study was preferred because the subject studied was a "general problem" or "situation" from real life, and the researchers aimed to examine a current, complex and special phenomenon within its own conditions. Another reason for choosing the qualitative case study design was to investigate a current issue in its natural environment in depth and to reach more accurate results by interpreting the findings together with quantitative findings (Cohen, Manion, and Morrison 2000; Creswell 2016; Platt 2007; Robson 2001; Williman 2006; Yin 2003). In the overall design of the study, the "exploratory sequential mixed research model" was used in which the quantitative data analysis is followed by qualitative data analysis (Axinn and Pearce 2006; Creswell and Clark 2015; Teddlie and Yu 2007). The quantitative and qualitative findings were combined and interpreted in the discussion part (Gardner 2012; Johnson and Onwuegbuzie 2004). This research design helps support quantitative findings with qualitative findings, and allows deeper insights into participant perceptions within their specific social contexts (Glesne 2015).

\subsection{Study group and Sampling}

The target population of the study is comprised of the academic staff employed in a state university in Turkey. The quantitative study group of the study consists of 238 participants selected from the population by the "simple random sampling" technique. The qualitative part applies the "critical case sampling," which is a purposive sampling technique based on a hypothesis that can be summarized as "if it happens here, it can happen in other similar situations" (Marczyk, DeMatteo, and Festinger 2005; Mertens 2014). The qualitative study group is composed of 14 managers selected from among the participants of the quantitative part. The qualitative data of the study were collected from the same sample from which quantitative data were collected. The qualitative data were collected through face-to-face interviews with 14 people considered to be experts on the subject and were in executive positions.

\subsection{Data Collection Tools}

The quantitative data of the study were collected by using the Workplace Spirituality Scale developed by Milliman, Gatling, Kim (2018), and the Five Factor Personality Scale developed by Somer and Goldberg (1999). These scales were adapted to Turkish by the authors. The qualitative data of the study was collected by means of a semi-structured interview form consisting of 3 main questions. The following questions were asked to the managers to obtain their opinions on personality traits and workplace spirituality:

1. What is your opinion on the importance of workplace spirituality, which means a set of acceptable principles, beliefs and values that employees have in the workplace?

2. What are your views on the possibility of a management style by considering personality traits in an environment where many people with different personality traits work?

3. To what extent do you think it is possible to align organizational spirituality values and individual traits in an organization where many people work?

\subsection{Validity and Reliability}

The Cronbach's Alpha internal consistency coefficients, which were calculated to determine the reliability of the scales of the study, are presented in Table 1.

The Cronbach's Alpha values of the scales related to personality traits were found to be between 0,626 and 0,792. The Cronbach's Alpha value of the 21-item workplace spirituality scale was found to be 0,860 . As these values were higher than 0,60 , it was concluded that the scales were reliable. The mean and standard deviation values of the scales are displayed in Table 2 .

Table 2 shows that the scores of the participants

Figure 1. Exploratory sequential mixed research model

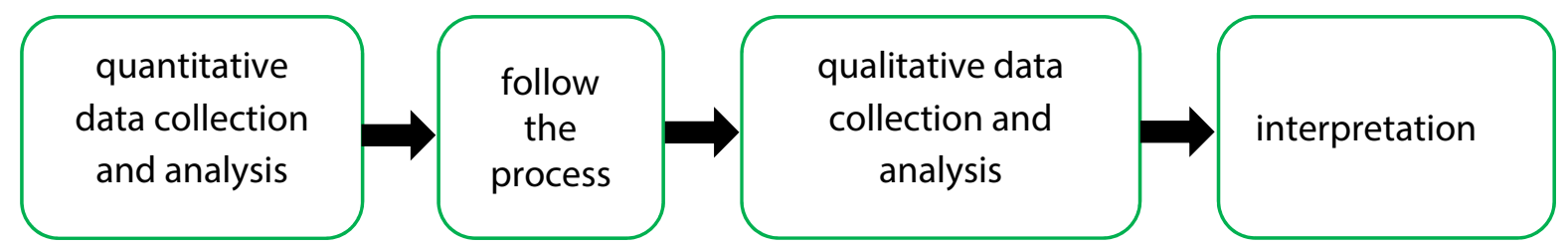


Table 1. Reliability Analysis Findings of Personality Traits and Workplace Spirituality Scales

\begin{tabular}{|c|c|c|}
\hline Variables & Cronbach's Alpha & Number of Items \\
\hline Openness & 0,65 & 4 \\
\hline Conscientiousness & 0,62 & 4 \\
\hline Extraversion & 0,72 & 4 \\
\hline Agreeableness & 0,69 & 4 \\
\hline Neuroticism & 0,79 & 4 \\
\hline Workplace Spirituality (Total Score) & 0,86 & 21 \\
\hline Meaningful Work & 0,67 & 6 \\
\hline Sense of Community & 0,69 & 7 \\
\hline Alignment with Organizational Values & 0,75 & 8 \\
\hline
\end{tabular}

Table 2. Mean and Standard Deviation of Personality Traits and Workplace Spirituality Dimensions

\begin{tabular}{|c|c|c|}
\hline Variables & Mean & Standard Deviation \\
\hline Openness & 3,87 & 0,70 \\
\hline Conscientiousness & 3,91 & 0,66 \\
\hline Extraversion & 3,71 & 0,78 \\
\hline Agreeableness & 3,90 & 0,68 \\
\hline Neuroticism & 2,74 & 0,97 \\
\hline Workplace Spirituality (Total Score) & 3,71 & 0,42 \\
\hline Meaningful Work & 3,91 & 0,49 \\
\hline Sense of Community & 3,70 & 0,50 \\
\hline Alignment with Organizational Values & 3,53 & 0,53 \\
\hline
\end{tabular}

related to personality traits, except neuroticism, are above average. These values indicate that the participants are innovative, emotionally balanced, outgoing, and harmonious. Likewise, it is observed that workplace spirituality values of the participants are above the average. The dimension with the highest score in the scale of workplace spirituality is "meaningful work" with a mean value of 3,92 (the scale is 5-point Likert Scale).

A confirmatory factor analysis was performed so as to determine the validity of the scales. The Workplace Spirituality Scale consists of 21 items under three dimensions. As the sum of the dimensions in the scale of personality traits did not constitute a separate concept, the analyses were conducted by evaluating each dimension as a separate scale (Neuroticism,
Agreeableness, Extraversion, Conscientiousness, Openness). Whether the structures were confirmed in the research sample was tested; The values of the scale were found to be satisfactory and it is indicated that the scales had construct validity. Additionally, convergent validity was tested using composite reliability (CR) and average variance extracted (AVE). AVE values are expected to be over 0,50 and lower than $C R$ values (Fornell and Larcker, 1981). The results of the analyses show that scales had convergent validity. The values for confirmatory factor analysis, composite reliability (CR) and average variance extracted are presented in Table 3.

Since validity in qualitative research can be both internal and external, the external validity and transferability of the obtained results in this study were

Table 3. Results of Construct and Convergent Validity Analyses

\begin{tabular}{c|c|c|c|c|c|c|c|c|c}
\hline Variables & CMIN & df & GFI & RMSEA & CFI & AGFI & NFI & CR & AVE \\
\hline Openness & 1,64 & 1 & 0,99 & 0,40 & 0,99 & 0,98 & 0,99 & 0,79 & 0,50 \\
\hline Conscientiousness & 0,72 & 1 & 0,99 & 0,00 & 0,99 & 0,99 & 0,99 & 0,80 & 0,50 \\
\hline Extraversion & 2,99 & 1 & 0,99 & 0,70 & 0,99 & 0,96 & 0,99 & 0,82 & 0,55 \\
\hline Agreeableness & 3,20 & 1 & 0,99 & 0,74 & 0,99 & 0,96 & 0,99 & 0,81 & 0,52 \\
\hline Neuroticism & 8,07 & 2 & 0,99 & 0,86 & 0,98 & 0,94 & 0,97 & 0,86 & 0,61 \\
\hline Workplace Spirituality & 600,98 & 186 & 0,86 & 0,74 & 0,81 & 0,83 & 0,75 & 0,88 & 0,62 \\
\hline
\end{tabular}


ensured by using multiple data sources (Leung 2015). The external validity was increased by resource and analyst diversity, and by quoting direct excerpts from the descriptive statements, while internal validity was achieved through participant confirmation and expert reviews (Creswell and Poth 2018; Merriam 2013). The overall reliability was ensured by verifying both internal and external reliability (Gardner 2012; Merriam 2013). The internal reliability was ascertained through consistency analysis, and the external reliability was confirmed through confirmation examination.

\subsection{Data Analysis}

In the quantitative part of the study, first, the Skewness Kurtosis Normal Distribution Test was applied to test the normal distribution of the data. Since the data were normally distributed (between $+1,5$ and $-1,5)$, parametric tests were performed (Tabachnick and Fidell 2013). The data were analyzed by applying the mean and standard deviation analysis, frequency analysis, Pearson correlation, and multiple regression analysis. The data collected for the qualitative part of the study were analyzed by qualitative content analysis. The main question and sub-questions were answered on the basis of the findings obtained from the qualitative content analysis. The researchers started the analysis without predetermined codes, and ascertained them during the analysis process (Brinkmann 2013). Thus, similar descriptive statements were grouped into certain concepts, codes, and themes (Gardner 2012).

\section{QUANTITATIVE FINDINGS}

To determine whether personality traits have a significant effect on workplace spirituality, frequency analysis, normality test, correlation analysis and multiple regression analysis were performed. The frequency analysis findings related to gender, marital status, education level, age, and work experience are shown in Table 4.

Table 4. The Distribution of Frequency and Percentage Related to the Demographic Characteristics of the Participants

\begin{tabular}{|c|c|c|c|}
\hline Variables & Category & Frequency & $\%$ \\
\hline \multirow{2}{*}{ Gender } & Female & 96 & 41,2 \\
\hline & Male & 137 & 58,8 \\
\hline \multirow{4}{*}{ Age } & $21-30$ years old & 13 & 5,6 \\
\hline & $31-40$ years old & 59 & 25,3 \\
\hline & 41-50 years old & 111 & 47,6 \\
\hline & 51 and above & 50 & 21,5 \\
\hline \multirow{2}{*}{ Marital Status } & Married & 181 & 77,7 \\
\hline & Single & 52 & 22,3 \\
\hline \multirow{3}{*}{ Work Experience } & $1-4$ years & 25 & 10,7 \\
\hline & 5-8 years & 95 & 40,8 \\
\hline & 9 years and above & 113 & 48,5 \\
\hline
\end{tabular}

Table 5. The Findings of Pearson Correlation Analysis to Examine the Relationship between Variables

\begin{tabular}{|c|c|c|c|c|c|c|c|c|}
\hline Dimensions & 1 & 2 & 3 & 4 & 5 & 6 & 7 & 8 \\
\hline 1. Opennes & - & & & & & & & \\
\hline 2. Conscientious-ness & $0,35^{* *}$ & - & & & & & & \\
\hline 3. Extraversion & $0,31 * *$ & $0,40 * *$ & - & & & & & \\
\hline 4. Agreeableness & $0,28^{* *}$ & $0,47^{* *}$ & $0,45^{* *}$ & - & & & & \\
\hline 5. Neuroticism & $-0,05$ & $-0,14^{*}$ & $-0,12$ & $0,25^{* *}$ & - & & & \\
\hline 6. Meaningful & $0,25^{* *}$ & $0,16^{* *}$ & $0,21^{* *}$ & $0,13^{*}$ & $0,17^{* *}$ & - & & \\
\hline 7. Sense of Community & $0,17^{* *}$ & $0,18^{* *}$ & $0,27^{* *}$ & $0,22^{* *}$ & $-0,05$ & $0,50 * *$ & - & \\
\hline 8. Alignment with Organizational Values & $0,25^{* *}$ & $0,14^{*}$ & $0,32^{* *}$ & $0,15^{*}$ & $-0,01$ & $0,52^{* *}$ & $0,62^{* *}$ & - \\
\hline 9. Workplace Spirituality. & $0,27^{* *}$ & $0,19^{* *}$ & $0,32^{* *}$ & $0,20 * *$ & $-0,09$ & $0,79 * *$ & $0,84^{* *}$ & $0,86^{* *}$ \\
\hline
\end{tabular}

* Correlation is meaningful at 0,05 level (2-tailed).

** Correlation is meaningful at 0,011 level (2-tailed). 
Regarding the personality traits, Skewness was found to be $-0,98$, and Kurtosis was found to be 1,45. Regarding the workplace spirituality, Skewness $(-0,99)$ and Kurtosis $(1,49)$ values were found to be between $-1,5$ and $+1,5$. Considering the normal distribution of the data on both variables, the analyses were performed by using parametric tests. Pearson Correlation analysis was conducted to investigate the relationship between the variables. The results of the analysis are shown in Table 5.

A statistically significant, positive and low-strength relationship was found between personality traits and workplace spirituality (total score and sub-dimensions), except neuroticism. These findings reveal that as the scores for openness, conscientiousness, extraversion and agreeableness increase, the total score of workplace spirituality increases, albeit weakly. To examine the effect of personality traits on workplace spirituality, a multiple regression analysis was applied by taking the personality traits as the independent variable, and assigning workplace spirituality as the dependent variable. Since neuroticism was not found to be significantly related to workplace spirituality, this dimension was excluded in the regression model. The findings are displayed in Table 6.
According to the Regression analysis, only the extraversion and openness as personal traits affect workplace spirituality to a significant degree. $\mathrm{R}^{2}$ value $(0,139)$ shows that the change in extraversion and openness explain $13,9 \%$ of the change in workplace spirituality. Extraversion and openness positively affect workplace spirituality at a low level (Beta $=0,248$; 0,179 ). Thus, the main hypothesis of the study was partially supported and the sub-hypotheses of $\mathrm{H} 1$ and $\mathrm{H} 3$ were accepted, but the $\mathrm{H} 2, \mathrm{H} 4$ and $\mathrm{H} 5$ were rejected. In the second step of the study, the opinions of 14 participant managers about how personality traits affect workplace spirituality and the possibility of taking personality traits into daily management practices were analyzed, as we discuss below.

\section{QUALITATIVE FINDINGS}

The demographic characteristics of the managers participating in the qualitative part of the study are shown in Table 7.

Through the first question, the executive opinions on how to relate the perception of workplace spirituality to personality structures were obtained. It was

Table 6. The findings of multiple regression analysis related to the effect of personality traits on workplace spirituality

\begin{tabular}{|c|c|c|c|c|c|c|}
\hline Independent Variable & $\mathbf{R}$ & $\mathbf{R} 2$ & Corrected R2 & Beta & $\mathbf{T}$ & $\mathbf{P}$ \\
\hline Openness & \multirow{4}{*}{0,373} & \multirow{4}{*}{0,139} & \multirow{4}{*}{0,124} & 0,179 & 2,658 & 0,008 \\
\hline Conscientiousness & & & & 0,021 & 0,284 & 0,777 \\
\hline Extraversion & & & & 0,248 & 3,437 & 0,001 \\
\hline Agreeableness & & & & 0,029 & 0,386 & 0,700 \\
\hline
\end{tabular}

Dependent Variable: Workplace Spirituality

Table 7. Demographic Characteristics of the Managers Participating in the Qualitative Part of the Research

\begin{tabular}{c|c|c|c}
\hline Participant Code & Marital Status & Age & Gender \\
\hline P1 & Married & 47 & Male \\
\hline P2 & Married & 53 & Male \\
\hline P3 & Married & 46 & Female \\
\hline P4 & Single & 39 & Male \\
\hline P5 & Married & 42 & Female \\
\hline P6 & Married & 56 & Male \\
\hline P7 & Single & 45 & Male \\
\hline P9 & Married & 49 & Female \\
\hline P10 & Married & 51 & Male \\
\hline P11 & Single & 56 & Male \\
\hline P13 & Married & 51 & Male \\
\hline P14 & Married & 53 & Female \\
\hline
\end{tabular}


intended to elicit managers' views on how to create a workplace spirituality that represents everyone in the workplace and that would be welcomed by everyone. The answers given to the question are presented in Table 8.

Six of the participants (42\%) stated that each person had a different personality structure and these differences gave them the identity of being a unique individual. According to the managers' opinions, it is natural that people perceive workplace spirituality differently due to having distinct personality structures. However, every employee needs workplace spirituality and achieves job satisfaction to the extent that this need is met. Some manager views on the question are as follows:

- Workplace spirituality is significant for everyone. P4

- People have spiritual needs as well as material needs. Workplace spirituality relates to the spiritual needs of people in the workplace. $P 9$

Nine of the participating managers (64\%) stated that even if people hold differing values, an organizational spirituality that appeals to and represents everyone can be established on the basis of "respect for human beings." The beliefs and values of people are different; however, the managers see a management approach based on certain standards, such as respect for rights, beliefs and thoughts, being remunerated for labor, and appreciation according to merit criteria possible. The participants stated that a workplace spirituality representing the beliefs and values of nearly everyone would be possible through such a management approach:

It's impossible to adopt as many management styles as the number of people's personality structures; however, a workplace spirituality that respects faith and values appeals to everyone. P5

Although the behaviors of people differ, their needs and basic tendencies are often common and they have spiritual needs. Workplace spirituality is a common value for everyone, even though it is perceived differently. P8

The second research question is about what managers think about the possibility of a management style by considering personality traits in an environment where many people with different personality traits work. Even though people have different personality structures, organizations are managed through a general management approach that does not take personality traits into account. The opinions of the managers regarding the question are shown in Table 9.

Eight (57\%) participants stated that human behavior, character, and ability should be taken into consideration while managing people. They also noted that it would be unrealistic to manage everyone in the same way. This perspective reveals that the participants

Table 8. The Opinions of Managers about Workplace Spirituality

\begin{tabular}{|c|c|c|c|c|c|}
\hline Descriptive Statements & Participants & $f$ & Code & Sub-theme & Main theme \\
\hline $\begin{array}{l}\text { Although workplace spirituality is per- } \\
\text { ceived differently, it is an important organi- } \\
\text { zational value needed by everyone. }\end{array}$ & $\begin{array}{l}\text { P2, P4, P7, P9, } \\
\text { P10, P13 }\end{array}$ & 6 & $\begin{array}{l}\text { Personality } \\
\text { structure } \\
\text { Workplace } \\
\text { spirituality }\end{array}$ & $\begin{array}{c}\text { Personality } \\
\text { and workplace } \\
\text { spirituality }\end{array}$ & \multirow{2}{*}{$\begin{array}{c}\text { Respect for } \\
\text { human values }\end{array}$} \\
\hline $\begin{array}{l}\text { Despite the fact that people's beliefs and } \\
\text { values are different, there is a common } \\
\text { aspect of respecting everyone's beliefs. }\end{array}$ & $\begin{array}{l}\text { P1, P3, P5, P8, P6, } \\
\text { P9, P10, P12, P14 }\end{array}$ & 9 & $\begin{array}{l}\text { Beliefs and } \\
\text { values } \\
\text { Respect for } \\
\text { faith }\end{array}$ & $\begin{array}{l}\text { Respect for } \\
\text { human }\end{array}$ & \\
\hline
\end{tabular}

Table 9. The views of managers on the importance of personality traits in management: frequency, code, sub-theme and main theme

\begin{tabular}{|c|c|c|c|c|c|}
\hline Descriptive Statements & Participants & $f$ & Code & Sub-theme & Main theme \\
\hline $\begin{array}{l}\text { Not all people understand the way you } \\
\text { speak; When managing them, it is impor- } \\
\text { tant to recognize their habits, abilities and } \\
\text { characters. In return, act accordingly. }\end{array}$ & $\begin{array}{c}\text { P2, P4, P5, P6, P7 } \\
\text { P9, P11, P14 }\end{array}$ & 8 & $\begin{array}{l}\text { Habit } \\
\text { Character } \\
\text { Ability }\end{array}$ & Personality & \multirow{2}{*}{$\begin{array}{l}\text { Management } \\
\text { of Personality }\end{array}$} \\
\hline $\begin{array}{l}\text { The artistic side of human management } \\
\text { is to get to know them at first glance and } \\
\text { utilize from their talents at maximum level. }\end{array}$ & $\begin{array}{l}\text { P2, P3, P6, P8, } \\
\text { P10, P13, P14 }\end{array}$ & 7 & $\begin{array}{l}\text { Management } \\
\text { Art } \\
\text { Ability }\end{array}$ & $\begin{array}{c}\text { Human } \\
\text { Management }\end{array}$ & \\
\hline
\end{tabular}


have an understanding that human resources management needs to consider personality structures rather than following a general human management approach. Some participant opinions are given below:

- Indeed, managing a person means managing his/her personality. Without this important element, it is impossible to make use of a person's skills. P2

- Human management is actually about the personality of people. Management is to use someone's abilities for the benefit of the organization. P11

It is clear that seven of the managers (50\%) have the opinion that human management is about the use of human knowledge, skills, and competences for the benefit of the organization. They also think that it is a must to recognize the character, talent, temperament, and personality type and take these features into account in management so as to benefit from human abilities and motivate employees at the maximum level. The managers are of the opinion that human management involves some human resources management and behavioral sciences aspects. Some participant views on this are as follows:

- Human management requires seeing into people at first glance and be a connoisseur of human nature. That is why it is very important to know the person you manage.P3

- Knowing people is the key because human management is not only about giving orders, but also finding talents and using them for the benefit of the organization. P10

The third research question focused on the harmony between organizational and individual values in human management and aimed to find out managerial views on the possible consequences of the match or mismatch between individual values and organizational values. The managers' opinions regarding this question are given in Table 10.

Six of the participants (42\%) stated that it is not the right approach to separate a person's life into private life and business life, or public and social life, and that people always have their own beliefs and values whatever the situation and wherever they live. Thus, some participants argued that an environment which runs counter to the beliefs and values of a person harms his/her personality and puts pressure on his/her character. Some statements expressing the above-mentioned opinion are as follows:

- It is not right to categorize human life as private and business life. $P 4$

- A human being is whole in terms of his/her personality; therefore, s/he does not show a different personality with respect to a different environment. $P 9$

Eight (57\%) of the participant managers reported that a management approach that respects the values of people and even sees it as richness will make a significant contribution to achieving job satisfaction and high performance by establishing a relationship between human values and organizational values. They think that human management cannot be executed only by instructions and strict rules; on the contrary, the artistic side of management is about revealing the talents within human beings for the benefit of the organization. Some participant opinions about the issue are as follows:

- Humans want to be present in every environment with their beliefs and values. No one can be asked to leave their values aside during their work hours. $P 8$

- There are tangible and intangible motivation and job satisfaction factors. Respecting human values in business life motivates them spiritually. P11

It is clear from these statements that it is important to consider the personality, character, and ability of a person in the human management decisions both to improve the individual performance of employees and organizational efficiency/effectiveness. Managers, on the other hand, share the common conviction that an organizational spirituality that respects basic values will appeal to everyone, despite the differences in personality traits.

Table 10. The views of managers related to the harmony between organizational and individual values

\begin{tabular}{|c|c|c|c|c|c|}
\hline Descriptive Statements & Participants & $f$ & Code & Sub-theme & Main theme \\
\hline $\begin{array}{l}\text { People want to live together with their } \\
\text { values in business life as well their private } \\
\text { life. }\end{array}$ & $\begin{array}{l}\text { P2, P4, P6, P9, } \\
\text { P11, P13 }\end{array}$ & 6 & $\begin{array}{l}\text { The values of busi- } \\
\text { ness and private } \\
\text { life }\end{array}$ & $\begin{array}{l}\text { Life style of } \\
\text { humans }\end{array}$ & \multirow{2}{*}{$\begin{array}{c}\text { Business life } \\
\text { of people }\end{array}$} \\
\hline $\begin{array}{l}\text { The harmony between human values and } \\
\text { corporate culture can contribute to the } \\
\text { achievement of job satisfaction and the } \\
\text { improvement of employee performance. }\end{array}$ & $\begin{array}{l}\text { P1, P3, P5, P7, } \\
\text { P8, P10, P11, } \\
\text { P13 }\end{array}$ & 8 & $\begin{array}{l}\text { The values } \\
\text { of human } \\
\text { Corporate culture } \\
\text { Job satisfaction }\end{array}$ & $\begin{array}{c}\text { Working life of } \\
\text { humans }\end{array}$ & \\
\hline
\end{tabular}




\section{DISCUSSION}

The findings reveal that the mean scores of perceptions related to personality traits, except neuroticism, are high. The personality perception dimension with the highest score is conscientiousness and the lowest is neuroticism. People seem willing to reveal their conscientiousness, while they seem reluctant to show neurotic personality traits because they are not widely approved. The participants also have high levels of workplace spirituality perception, with the highest-scoring dimension being meaningful work, and the lowest being alignment with organizational values. The findings also reveal that personality structure causes a difference in the perception of organizational spiritual climate and values. The low level of positive harmony perception between values indicate that organizational values do not adequately reflect the views of the participants. The possible negative consequences of this may be inadequate job satisfaction and employee performance, the increase in anti-productivity behaviors, and stronger intention to quit the job. Lawrence and Callan (2011) found that a highly positive workplace spirituality perception substantially improves job satisfaction and performance. Furthermore, Lazar (2016) found a strong relationship between workplace spirituality and openness-conscientiousness. All the personality traits, except neuroticism, have a positive and statistically significant relationship with workplace spirituality. When the effects of the personality traits on workplace spirituality are examined, it is evident that openness and extroversion have a positive impact on workplace spirituality, but responsibility and agreeableness have no effect on it. Given that extrovert people have a high level of interaction abilities with their superiors, subordinates and other colleagues, extrovert people's highly positive perceptions of workplace spirituality is an expected outcome. In a study with a larger sample of administrative and academic staff, a significant effect of extraversion was found on workplace spirituality (Tutar and Oruc 2020). Therefore, extrovert employees who are open to innovations have much more positive perceptions of workplace spirituality, motivating them for organizational change and innovation.

Kolodinsky, Giacalone, and Jurkiewicz (2008) found that workplace spirituality contributed significantly to reducing the frustration of employees at work. Some studies show that there is a strong positive relationship between personality dimensions and job performance, which indicates that workplace spirituality needs to be regulated by taking the personality traits of employees into account for organizational efficiency and effectiveness (Barrick, Mount, and Judge 2001; Liao and Chuang 2004). Although workplace spirituality differs by personality traits dimensions, other studies support our conclusion that workplace spirituality positively correlates with agreeableness, extroversion, openness, and conscientiousness (Garcia-Zamor 2003). Afsar and Rehman (2015) suggest that positive perceptions of workplace spirituality strengthen employees' feelings of cooperation, generating creative organizational culture with high representation skills, and creating a mutual sense of commitment and trust among employees.

\section{CONCLUSION}

Our findings indicate that the harmony between the perception of personality structures and workplace spirituality has an important function in the adoption of workplace values by the employees. Rego, Cunha, and Oliveira (2008) found that positive perceptions of workplace spirituality strengthen the organizational commitment of the employees and increases their organizational performance and productivity. Besides, the obtained results clearly support the conclusion that positive workplace spirituality perceptions favor the secondary dimensions of organizational commitment, internal job satisfaction, involvement in the job, organizational based self-esteem, and reduced intention to quit job. Some other studies have found that positive workplace spirituality perceptions reduce organizational stress and prevent the emergence of anti-productivity behaviors (Altaf and Awan 2011; Rego and Cunha 2008). Further, those who have highly positive perceptions of workplace spirituality display stronger organizational citizenship behaviors and are more willing to behave ethically compared to others (Lips-Wiersma and Mills 2002). A highly favorable perception of workplace spirituality strengthens employees' sense of responsibility, leading them to be more willing to exhibit proactive behaviors (Khan, Khan, and Chaudhry 2015). The findings of the current study indicate that a highly positive perception of workplace spirituality is important in terms of individual and organizational productivity. However, not everyone assigns the same meaning to the same situation; every employee may perceive workplace spirituality differently depending on their unique personality. Consequently, it is vital to consider human management not only in terms of principles, rules, and norms, but also in terms of personality traits. The managers in this study share the opinion that a workplace spirituality model for each personality trait cannot be created, but a management approach respecting the basic beliefs and values of everyone is possible.

Our study is limited to the relationship between the 
five-factor model of personality and workplace spirituality. Repeating the study with different study groups may increase its generalizability. This cross-sectional study can be repeated longitudinally through metaanalyses. In future research, workplace spirituality and personality traits can be tackled together with secondary characteristics of workplace spirituality. Finally, a person's inclination towards religiosity, job stress, anti-productivity behaviors, absenteeism, perceived organizational support and organizational citizenship can be analyzed by considering organizational trust variables, along with regulatory and mediator variables. As a final note, the readers should be aware that the results of this study are limited to data obtained from a particular study group. It is important for administrators to be aware that the results obtained and the opinions reported are limited to a certain sample, and the qualitative part in particular reflects the subjective judgments of the researchers.

\section{REFERENCES}

Afsar, B. and Rehman, M. 2015. The relationship between workplace spirituality and innovative work behavior: The mediating role of perceived person-organization fit. Journal of Management, Spirituality and Religion 12: 329-353.

Altaf, A. and Awan, M. A. 2011. Moderating effect of workplace spirituality on the relationship of job overload and job satisfaction. Journal of Business Ethics 104 (1): 93-99.

Ashmos, D. P. and Duchon, D. 2000. Spirituality at work: A conceptualization and measure. Journal of Management Inquiry 9 (2): 134-145.

Axinn, W. G. and Pearce, L. D. 2006. Mixed method data collection strategies. New York: Cambridge University Press.

Barrick, M. R., Mount, M. K. and Judge, T. A. 2001. The FFM personality dimensions and job performance: MetaAnalysis of meta-analyses. International Journal of Selection and Assessment 9: 9-30.

Bozionelos, N. 2004. The big five of personality and work involvement. Journal of Managerial Psychology 19 (1): 69-81.

Brinkmann, S. 2013. Qualitative interviewing: Understanding qualitative research. New York: Oxford University Press.

Burger, J. M. 2008. Personality (7th edition). Belmont, CA: Wadsworth.

Creswell, J. W. 2012. Educational research: Planning, conducting, and evaluating quantitative and qualitative research (4th edition.). Upper Saddle River, NJ: Pearson

Creswell, J. W. and Clark V. L. P. 2015. Designing and conducting mixed methods research (3th edition). Thousand Oaks, CA: Sage.

Creswell, J. W. and Garrett, A. L. 2008. The movement of mixed methods research and the role of educators. South African Journal of Education 28 (3): 321-333.
Creswell, J. W. and Poth, C. N. 2018. Qualitative inquiry and research design choosing among five approaches. USA: SAGE.

Cohen, L., Manion, L. and Morrison, K. (2000). Research Methods in Education, (5th edition). Abingdon: Routledge Falmer.

Daniel, J. L. 2010. The effect of workplace spirituality on team effectiveness. Journal of Management Development 29: 442-456.

Duffy, R. D., Blustein, D. L., Diemer, M. A. and Autin, K. L. 2016. The psychology of working theory. Journal of Counseling Psychology 63 (2): 127-148.

Fornell, C. and Larcker, D. F. 1981. Evaluating structural equation models with unobservable variables and measurement error. Journal of Marketing Research 18 (1): 39-50.

Garcia-Zamor, J. C. 2003. Workplace spirituality and organizational performance. Public Administration Review 63 (3): 355-363.

Gardner, M. K. 2012. Mixed-methods research. In How to design and evaluate research in education, edited by $\mathrm{J}$. R. Fraenkel, N. E., Wallen and H. H. Hyun, 555-586. USA: McGraw-Hill.

Giacalone, R. A. and Jurkiewicz, C. L. 2003. Toward a Science of Workplace Spirituality. In The handbook of workplace spirituality and organizational performance, edited by $R$. A. Giacalone and C. L. Jurkiewicz, 3-28. NY: M.E. Sharpe.

Glass, R., Prichard, J., Lafortune, A. and Schwab, N. 2013. The influence of personality and facebook use on student academic performance. Issues in Information Systems 14 (2): 119-126.

Glesne, C. 2015. Becoming qualitative researchers: An introduction (5th edition). White Plains, NY: Longman.

Goldberg, L. R. 1981. Language and individual differences: The search for universals in personality lexicons. Review of Personality and Social Psychology 2 (1): 141-165.

Hough, L.M. and Ones, D. S. 2001. The structure, measurement, validity and use of personality variables in industrial work and organizational psychology. In Handbook of industrial work and organizational psychology, Vol. 1. Personnel psychology, edited by N. Anderson, D. S. Ones, H. K. Sinangil and C. Viswesvaran, 233-277. NY: Sage Publications.

John, M., Andrew, J. C. and Jeffery, F. 2003. Workplace spirituality and employee work attitudes. An exploratory empirical assessment. Journal of Organizational Change Management 16 (4): 426-447.

John, O. P., Naumann, L. P. and Soto C. J. 2008. Paradigm shift to the integrative big-five trait taxonomy: History, measurement and conceptual issues. In Handbook of personality. Theory and research, edited by O. P. John, R. W. Robins and L. A. Pervin, 114-158. New York: Guilford Press.

Johnson, B. and Christensen, L. 2004. Educational research: Quantitative, qualitative, and mixed approaches (2th edition.). Needham Heights, MA: Allyn ve Bacon.

Johnson, R. B. and Onwuegbuzie, A. J. 2004. Mixed methods research: A research paradigm whose time has come. Educational Researcher 33 (7): 14-26. 
Khan, K. E., Khan, S. E. and Chaudhry, A. G. 2015. Impact of servant leadership on workplace spirituality: Moderating role of involvement culture. Pakistan Journal of Science 67: 109-113.

Kinjerski, V. A. L. and Skrypnek, B. J. 2006. A human ecological model of spirit at work. Journal of Management, Spirituality and Religion 3 (3): 231-241.

Kolodinsky, R.W., Giacalone, R.A. and Jurkiewicz, C.L. 2008. Workplace values and outcomes: Exploring personal, organizational, and interactive workplace spirituality. Journal of Business Ethics 81 (2): 465-480.

Lazar, A. 2016. Personality, religiousness and spirituality-interrelations and structure-in a sample of religious Jewish women. Mental Health, Religion and Culture 19 (4): 307-322.

Lawrence, S. A. and Callan, V. J. 2011. The role of social support in coping during the anticipatory stage of organizational change: A test of an integrative model. British Journal of Management 22 (4): 567-585.

Leung, L. 2015. Validity, reliability, and generalizability in qualitative research. Journal of Family Medicine and Primary Care 4 (3): 324-327.

Liao, H. and Chuang, A. 2004. A multilevel investigation of factors influencing employee service performance and customer outcomes. Academy of Management Journal 47 (1): 41-58.

Lips-Wiersma, M. and Mills C. 2002. Coming out of the closet: Negotiating spiritual expression in the workplace. Journal of Managerial Psychology 17: 183-202.

Marczyk, G., DeMatteo, D. and Festinger, D. 2005. Essentials of research design and methodology. New York: John Wiley and Sons Inc.

McCrae, R. R. and Costa, P. T. 2003. Personality in adulthood a five-factor theory perspective (2th edition). New York: Guilford Press.

Merriam, S. B. 2013. Qualitative research: A guide to design and implementation. New York: John Wiley and Sons Inc.

Mertens, D. M. 2014. Research and evaluation in education and psychology: Integrating diversity with quantitative, qualitative, and mixed methods. New York: Sage.

Milliman, J., Czaplewski, A. J. and Ferguson, J. 2003. Workplace spirituality and employee work attitudes: An exploratory empirical assessment. Journal of Organizational Change Management 16 (4): 426-447.

Milliman, J., Gatling, A. and Kim, J. S. 2018. The effect of workplace spirituality on hospitality employee engagement, intention to stay, and service delivery. Journal of Hospitality and Tourism Management 35: 56-65.

Mitroff, I. I. and Denton, E. A. 1999. A spiritual audit of corporate America: $A$ hard look at spirituality, religion, and values in the workplace. San Francisco, CA: Jossey-Bass.

Nasina, M. D., Pin, D. and Pin, K. 2011. The workplace spirituality and affective commitment among auditors in big four public accounting firms: Does it matter? Journal of Global Management 2 (1): 216-226.

Neal, J. and Biberman, J. 2003. Introduction: The leading edge in research on spirituality and organizations. Journal of Organizational Change Management 16 (4): 363-366.

Patton, M. Q. 2014. Qualitative research and evaluation methods: Integrating theory and practice (4th edition). Thousand Oaks, CA: Sage Publications.

Petchsawang, P. and Duchon, D. (2009). Measuring workplace spirituality in an Asian context. Human Resource Development International 12 (4): 459-468.

Piryaei, S. and Zare, R. 2013. Workplace spirituality and positive work attitudes: The moderating role of individual spirituality. Indian Journal of Economics and Development 1:91-97.

Rego, A., Cunha, M.P.E. and Oliveira, M. 2008. Eupsychia revisited: The role of spiritual leaders. Journal of Humanistic Psychology 48 (2): 165-195.

Rego, A. and Cunha, M. P. E. 2008. Workplace spirituality and organizational commitment: an empirical study. Journal of Organizational Change Management 21 (1): 53-75.

Saks, A. M. 2011. Workplace spirituality and employee engagement. Journal of Management Spirituality and Religion 8 (4): 317-340.

Sheng, C. W. and Chen. M. C. 2012. Chinese viewpoints of workplace spirituality. International Journal of Business and Economics 3 (2): 31-42.

Somer, O. and Goldberg, L. R. 1999. The structure of Turkish trait descriptive adjective. Journal of Personality and Social Psychology 76 (3): 421-450.

Tashakkori, A. and Teddlie, C. 2003. The past and future of mixed methods research: From data triangulation to mixed model designs. In Handbook of mixed methods in social and behavioral research, edited by A. Tashakkori and C. Teddlie, 671-701. Thousand Oaks, CA: Sage.

Tabachnick, B. G. and Fidell, L. S. 2013. Using multivariate statistics. (6th edition) Boston: Pearson.

Teddlie, C. and Yu, F. 2007. Mixed methods sampling: A typology with examples. Journal of Mixed Methods Research 1 (1): 77-100.

Tett, R. P., Jackson, D. N. and Rothstein, M. 1991. Personality measures as predictors of job performance: A meta-analytic review. Personnel Psychology 44 (4): 703-742.

Tutar, H. and Oruç, E. (2020). Examining the effect of personality traits on workplace spirituality. International Journal of Organizational Analysis 28 (5): 1005-1017.

Witt, L., Burke, L. A., Barrick, M. R. and Mount, M. K. 2002. The interactive effects of conscientiousness and agreeableness on job performance. Journal of Applied Psychology 87 (1): 164-169.

Yin, R. K. 2014. Case study methods: Design and methods (5th edition). Thousand Oaks: Sage Pub. 